\title{
DINARES, DIRHAMES Y FELUSES. CIRCULACIÓN MONETARIA EN EL PAÍS VALENCIANO I Carolina Doménech Belda
}

(Publicaciones Universidad de Alicante, Serie Arqueología, Salamanca, 2003).

Desde hace poco más de 20 años la Numismática Andalusí ha resurgido de sus cenizas cual Ave Fenix, retomando las investigaciones comenzadas en el siglo XVIII con Casiri y Banqueri, continuadas a principios del XIX con Conde y que alcanzaron su máximo esplendor con Delgado y con sus sucesores Codera, Vives y Prieto y Vives entre los más importantes. Esta disciplina sufre un retroceso a partir de la muerte de Prieto y Vives en 1939 y será retomada a partir del último cuarto del siglo $X X$, engrandeciéndose con la celebración del I Jarique de Estudios Numismáticos Hispano-Árabes celebrado en Zaragoza en 1988, con los sucesivos Jariques, y con nuevos investigadores entre los que destacan Miquel Barceló, Juan Ignacio Sáenz Díez, Alberto Canto, Tawfiq Ibrahim, Josep Pellicer y Salvador Fontela, entre otros, que han sabido darle un enfoque no sólo numismático sino también histórico y arqueológico.

Sus trabajos correspondían a estudios de hallazgos concretos e incluso de piezas individualizadas, a estudios metrológicos, a momentos históricos determinados, a reformas concretas o actuaciones puntuales de los ashāb al-Sikka, (como ejemplo veáse BARCELÓ, 1988; SÁENZ DÍEZ, 1980; CANTO, 1986; IBRĀHITM, I99।; PELLICER, 1989, FONTELA, 1986 y MEDINA, 1992) utilizando como manuales las obras imprescindibles de Conde (CONDE, 1817) y Codera (CODERA, 1879) ${ }^{2}$. Sin querer desplazar a las obras anteriores, Canto e Ibrāhīm publicaron en 1997, con motivo de la exposición que se realizó en la Alhambra sobre moneda andalusí ${ }^{3}$, un catálogo de la misma en el que los capítulos introductorios reflejan el estado de la cuestión, constituyendo un manual en sí mismos. Este trabajo es el único, junto a la obra de Medina (MEDINA, 1992), que podíamos considerar, de los publicados tras la remesa de Codera y compañía, como un manual introductorio a la numismática andalusí, hasta la publicación del libro que aquí reseñamos.

La autora, Carolina Doménech, profesora del Área de Arqueología de la Universidad de Alicante, es espe- cialista en Numismática Islámica y en 1997 leyó su tesis doctoral Circulación monetaria durante el periodo islámico en el País Valenciano, tesis que ha sido adaptada para esta publicación.

Alberto Canto, codirector de la tesis doctoral, dice que esta obra: "ha abierto una puerta en una dirección nueva: realizar un análisis de la circulación monetaria en un territorio determinado, combinando tanto los datos proporcionados por los hallazgos y los depósitos de material numismático en los museos, como por el registro sistemático de la presencia de monedas en las diferentes excavaciones arqueológicas realizadas en el territorio estudiado, así como la mención de todo aquel material susceptible de ser estudiado del que se pudiera constatar la procedencia (como es el caso de la colecciones locales) (...), por vez primera se dispone de un registro fiable y en extensión de la actividad monetaria en un determinado territorio de Al-Andalus" ${ }^{4}$.

El libro se estructura en tres partes bien diferenciadas; en la primera y modo de introducción expone la metodología utilizada, una breve reseña histórica y como se organiza el estudio. El punto neurálgico es el análisis que realiza de todos los conjuntos monetarios o piezas aisladas de cronología andalusí halladas en el País Valenciano. En total recoge 106 hallazgos entre conjuntos monetales, acumulaciones de numerario y hallazgos aislados. Todo forma un conjunto de 5900 piezas sobre las que trabaja; en estas se incluyen las piezas con datos y las piezas de las que solo se conoce su existencia.

La Dra. Doménech considera que todo estudio de circulación monetaria debe basarse en una exahustiva recopilación de los hallazgos monetarios, y asílleva a cabo su estudio. Los ordena de modo geográfico, de Norte a Sur y a final de cada provincia los de localización imprecisa. No todos han podido ser consultados físicamente por la autora, aunque también recoge los hallazgos o piezas que tan sólo están documentadas por referencias bibliográficas.

I Esta reseña ha sido realizada por Teresa Campos López y Fátima Martín Escudero.

2 El estudio más completo de numismática andalusí, realizado por Antonio Delgado, aunque escrito en el tercer cuarto del siglo XIX, no ha sido editado hasta 2002. (DELGADO, 2002).

3 Moneda andalusí en la Alhambra. Palacio de Carlos V, Granada. Marzo-agosto 1997. Los comisarios de la exposición fueron Alberto Canto García y Tawfiq ibn Hāíz Ibrāhìm.

4 Canto García, Alberto: Prólogo a la obra de la Carolina Doménech Belda: Dinares, dirhames y feluses. Circulación monetaria en el País Valenciano. Salamanca, 2003. p. 13. 
Realiza buenos comentarios críticos de los hallazgos, referencias del conjunto y análisis de piezas individuales e interesantes interpretaciones arqueológicas de los conjuntos que están relacionados con un yacimiento concreto, aportando datos arqueológicos y comentario sobre las excavaciones y los materiales asociados para ver si concuerdan con las piezas halladas, como ocurre con el hallazgo de Muntayeta de Sant Josep de Vall d'Uixò ( $n^{\circ} 31$ ). Como es lógico, cuando examina un conjunto monetario con más información, este se encuentra mejor estudiado, pero en pocas ocasiones ofrece conclusiones sobre su motivo de ocultación aunque sí sobre cuándo estas fueron ocultadas, sobre los problemas numismáticos que estas piezas plantean y su posible solución, como ocurre con los feluses de Ibn Bahlūl y Galaba en el hallazgo de Muchamiel ( $\left.n^{\circ} 83\right)$.

Entre los hallazgos cabe reseñar algunos cuya importancia es especialmente significativa, como el de Castellet de Xilxes ( $\left.n^{\circ} 32\right)$ al ser uno de los pocos conjuntos bimetálicos de época andalusí, compuesto por fracciones de dinar y dirhames taifas; en Sagunto ( $\left.n^{\circ} 36\right)$ donde apareció un dinar latino de época de conquista; El Fortí de Denia ( $\left.n^{\circ} 58\right)$ con dirhames de los Banū Ganiyā; el de Benichembla $\left(n^{\circ} 64\right)$ que presenta una amplia cronología desde el siglo IX al XIII; Benidorm Casco Urbano ( $\left.n^{\circ} 73\right)$ con cuartos de dinar del califa fatimí de Al-Mustanšir y el hallazgo de Elche Casco Urbano ( $n^{\circ}$ 93) en el que aparecen dirhames califales recortados siguiendo patrones fatimíes. Hay una falta de documentación respecto a Valencia ciudad debido a que el $\mathrm{SIAM}^{5}$ del Ayuntamiento de Valencia no permitió el acceso a sus fondos museísticos.

Esta parte de la obra parece más bien realizada para una consulta precisa de un hallazgo concreto, que al seguir la ordenación ya indicada, resulta confuso y quizás una ordenación cronológica hubiera hecho que la lectura del mismo hubiese sido más amena y hubiera conseguido mantener el hilo de la redacción más coherente, al no ir saltando de un periodo cronológico a otro continuamente. Además la ordenación geográfica aquí poco aporta ya que en este apartado de la obra no se realiza interpretación alguna de la circulación monetaria.

Quizás se eche en falta una descripción más detallada de las piezas, sin recurrir exclusivamente a un número de referencia en un catálogo, ya que así la referencia a piezas variantes sería más comprensible, al igual que si la exposición de la composición de los hallazgos se hubiese realizado en tablas, se hubiese conseguido una presentación más visual y esquemática. Así mismo se agradece la presencia y buena calidad de las imágenes de las piezas más destacadas, como de los gráficos y dibujos cerámicos.
En la segunda parte y según la autora "se ha procedido a la ordenación de las series por periodos siguiendo una secuencia estrictamente cronológica. Estas series, ordenadas y colocadas en un mapa evidencia distintas áreas monetarias para cada uno de los momentos" 6 . Consigue dar una visión general de la evolución de la circulación monetaria a lo largo de cada periodo histórico.

No solo subdivide esta sección en los periodos establecidos por la historiografía tradicional ${ }^{7}$, sino que inicia su estudio desde el final de la presencia romana en el País Valenciano y lo concluye con los momentos anteriores a la conquista cristiana y un apartado especial para la moneda no andalusí de tradición islámica como lo fueron las dinastías Hafsí, Fatimí y Mariní, todas ubicadas al otro lado del estrecho de Gibraltar.

A pesar de mantener unos temas a tratar en cada uno de los subperiodos, intentar adaptar cada capítulo a su realidad histórica y a la respuesta de una serie de preguntas. En cada uno comienza con una breve reseña histórica y una alusión a las fuentes documentales y bibliográficas; explica de una manera concisa la tipología monetaria, sus orígenes, evolución y particularidades; presenta diferentes teorías surgidas ante un mismo problema numismático, pero sin aportar su visión personal y recurre a las piezas ya presentadas en los análisis de los hallazgos, para realizar, de un modo, en nuestra opinión, algo breve, una interpretación de la circulación monetaria en cada subperiodo.

Cuando aborda el mundo romano es interesante constatar el uso de su numerario en bronce desde el siglo IV al VIII, a veces asociado a feluses emirales, como ocurre en el Tolmo de Minateda en Hellín. Igualmente significativa es su teoría sobre la circulación monetaria de este periodo asociada con la llegada de norteafricanos, pero deberíamos preguntarnos si este hecho también ocurre en la Bética, zona donde hubo mayor circulación monetaria en estos momentos.

Interesantes son las interpretaciones acerca de la ocupación del territorio que ofrece basándose en los hallazgos de cada zona y periodo: la moneda vándala aparece en la costa, a donde llegaba; o respecto a la moneda visigoda, que sus acuñaciones marcan el momento en el que la zona dejó de estar bajo influencia bizantina.

Se acerca al mundo de la conquista y el emirato dependiente realizando una excelente explicación de la problemática de la acuñación de los primeros dinares que aparecen en la Península, pero al tratar la problemática de dónde se acuñan los dirhames reformados no documenta la existencia de un dirham del año $136 \mathrm{H}$. y la teo-

\footnotetext{
5 Servicio de Investigación Arqueológica Municipal.

6 Doménech Belda, Carolina: Dinares, dirhames y feluses. Circulación monetaria en el País Valenciano. Salamanca, 2003. Pp.20.

7 Conquista y Emirato Dependiente, Emirato Independiente, Califato, Taifas Califales, Almorávide, Taifas Almorávides, Almohades, Taifas Almohades y Nazaríes.
} 
ría sobre la acuñación de estas monedas que contraria a la de Barceló (BARCELÓ, 1988), esta pieza suscita (MARTÍN ESCUDERO, 200I).

En este apartado expone de manera clara las distintas problemáticas de los feluses: uno, los problemas cronológicos para identificar estas piezas como de Conquista o del Emirato Independiente. Otro, el de los talleres de acuñación aunque este apartado, a pesar de su título, trata más de la tipología de las distintas piezas. Nos sorprende que no se haga ninguna alusión a los trabajos de Rafael Frochoso (FROCHOSO 1996 y 1997) relativos a estos tipos monetarios.

Para el Emirato Independiente Doménech estructura el estudio en función de un modelo de circulación trimetálico en contra de lo que se venía considerando y que gracias a las aportaciones de Canto se establece que el sistema acepta la moneda de oro aglabí como un circulante válido. En la moneda de plata, el dirham, aborda el tema de su uso como moneda fiscal y comercial y el problema del fraccionamiento de moneda. La autora señala la existencia de pocos hallazgos en este periodo, lo que explica que estamos ante una sociedad poco monetizada y con una estructura económica simple. Respecto a los feluses, destaca su teoría del Ibn Bahlūl, rebelde muladí que se levanta contra el poder omeya, sufraga las obras de la mezquita de la rábita de Guardamar y acuña moneda.

Realiza un compendio de las antiguas y nuevas teorías sobre el numerario califal, aportando el estudio de las piezas en el País Valenciano y la interpretación que por ellas plantea sobre la circulación monetaria. Se apoya en el centralismo califal para desbancar la teoría de Martínez Salvador (MARTíNEZ SALVADOR, 1995) en la que establece que la profusión de motivos decorativos geométricos y vegetales en las monedas corresponden a una multiplicidad de cecas.

Continúa con las taifas califales estableciendo que a partir del segundo tercio del siglo XI aparece el numerario de estos estados plenamente independiente, tras la aparición del falso Hišāàm II en la taifa de Sevilla, y así justifican sus acuñaciones al aludir a él como califa y emitir moneda como prerrogativa califal donde ellos aparecen como hâyibes. Se alude a la fiscalidad ilegal y a la alta presión fiscal a la que se somete a los súbditos.

Aspectos que nos han llamado gratamente la atención han sido el tratamiento del tema de la taifa de Elota y su ubicación geográfica, a través de las fuentes docu- mentales, la arqueología y la dispersión geográfica de sus monedas; y el estudio pormenorizado de la taifa de Valencia. Sin embargo en ocasiones el texto parece confuso debido a la profusión de nombres de gobernantes y la no especificación de quién es quién.

Aborda el cambio de mentalidad almorávide y su reflejo en la fiscalidad, estrictamente coránica y unitaria, y en la moneda, cambios que se aprecian en la buena ley y el nuevo mensaje que aportan ${ }^{8}$. En este capítulo se acerca al tema de las distintas cecas del territorio comparándolo con territorios cercanos. En lo que al estudio de los hallazgos se refiere no lleva un orden estipulado, pasando de hallazgos áureos a un análisis por piezas y gobernantes.

Los Almohades imponen una desviación radical respecto a las políticas monetarias del mundo islámico; entre estas reformas se dobla el peso del dinar y se instituye la forma cuadrada para el dirham. Doménech no trata el tema de la epigrafía monetal hasta ahora, distinguiendo entre la escritura cúfica, la utilizada hasta el momento, y la nueva nesjí.

Concluye su periplo histórico-numismático aproximándose a la realidad numismática de los reinos andalusíes de Ibn Mardaniš, Ibn Hūd e Ibn Nașr, y a los norteafricanos Hafsí, Fatimí y Mariní, que aunque quedando fuera de la esfera geográfica del estudio, aportan monedas al mismo, y con ellos finaliza desde el punto de vista de la evolución numismática su estudio.

En la tercera y última parte en que podemos dividir este libro hallamos una bibliografía completa y actualizada, una tabla de materiales con 3432 registros de las piezas documentadas y de las que se conoce algún dato 9 . Cierra el libro un apéndice de leyendas de determinadas monedas insertas en el estudio y una addenda con los últimos hallazgos.

Consideramos, a modo de apreciación personal, que el orden del libro debería ser el inverso, comenzando con la evolución histórica y la descripción de las piezas desde un punto de vista cronológico y formal y tras una idea general pasar al comentario pormenorizado de los hallazgos.

Es de agradecer a la autora la actualización bibliográfica que ha realizado a la obra, escrita como tesis doctoral en 1997 y publicada 6 años después. En la addenda además incluye hallazgos o novedades que cree convenientes para su investigación.

8 Sura 3, aleya 85 que expresa la superioridad del Islam y hay un reconocimiento expreso al Califa Abbasí.

9 Se hace referencia al número de cada pieza dentro del trabajo general, lugar de conservación, lugar de aparición, yacimiento, si lo hubiese o este dato estuviese documentado, y todas las características tipológicas de la moneda como son su denominación, metal, estado de conservación (entera, fragmentada, o sólo círculo central), alteraciones tales como perforaciones, grapas..., periodo al que pertenece, Estado, gobernante, ceca y fecha de acuñación, y características físicas tales como el peso, módulo, grosor y posición de los cuños. 
No obstante, a modo de pequeño comentario señalar que no se observa, en ocasiones, un criterio fijo en las citas bibliográficas ${ }^{10}$, en la presentación de los nombres árabes a veces transcritos, otras no "', en la cita de fechas 12; en ocasiones introduce abreviaturas que no desarrolla tanto de personas como de instituciones ${ }^{13}$, o la utilización esporádica de términos un tanto ambiguos como el caso de peso neto y peso bruto referido a las monedas ${ }^{14}$ y otras erratas comunes.

Este libro, resultado de su tesis doctoral, pretende, creemos, ser un estudio de la circulación monetaria de un territorio, en este caso el País Valenciano, a través del estudio de las monedas conservadas o, mejor dicho, documentadas. Esta intención queda vagamente reflejada en el libro que se convierte en un muy completo manual de numismática por 1.- las amplias y muy completas e interesantes presentaciones históricas y numismáticas de cada etapa política dentro de Al-Andalus, y 2.- las vagas alusiones a las piezas halladas en cada territorio, hecho quizás motivado por la reducción de páginas al convertir la tesis en algo editable, o por la escasez de datos en otros momentos.

Alegremente se reciben este tipo de trabajos innovadores y de esta envergadura dentro de la numismática andalusí, que se está centrando no en aspectos tan generales y más en particularidades. Este ingente estudio debería desarrollarse en todas las zonas de influencia andalusí para así, esperemos que en un futuro no muy lejano, poder conocer con más detalle la circulación monetaria de cada territorio y de Al-Andalus en general, lo que nos llevará a un mejor entendimiento de una realidad histórica compleja.

Teresa Campos López y Fátima Martín Escudero

\section{BIBLIOGRAFÍA}

BARCELO, M. "Coins from afar?. New evidence on coin production and fiscal administrative practice in the late Umayyad caliphate", Problems of Medieval Coinages in the Iberian Area, 3. Santarem, 1988. Pp. 107-1।8.

CANTO GARCIA, A. "La reforma monetaria de Qasim", Al-Qantara, 7. Madrid, 1986. Pp. 403-29.
CANTO GARCÍA. Alberto e IBN HĀFIZ IBRĀHIMM, Tawfíq: Moneda andalusí en la Alhambra. Sevilla, 1997

CODERA Y ZAIDIN, F. Tratado de numismática arábigoespañola, Madrid, Librería M. Murillo, I879, XXII pp., । hoj., 319 pp., 24 láms.

CONDE, J. A. "Memoria sobre la moneda arábiga y en especial la acuñada en España por los Príncipes Musulmanes (leída en la Real Academia de la Historia, en Junta de 21 de julio de 1804 )", Memorias de la Real Academia de la Historia, V. 1817.

DELGADO HERNÁNDEZ, A.: Estudios de Numismática Hispano-Árabe como comprobante de la dominación islámica de la Península. Canto García A. et Ibn Hāfiz lbrāhīm, T. (eds.). Real Academia de la Historia. Madrid.

DOMÉNECH BELDA, C.: Dinares, dirhames y feluses. Circulación monetaria en el País Valenciano. Salamanca, 2003.

FONTENLA BALLESTA, S.: "Monedas inéditas de las Taifas almohades", Gaceta Numismática, 82. 1986. Pp. 63-68.

FROCHOSO SANCHÉZ, R.: "Los feluses del periodo de los gobernadores omeyas en Al-Andalus", Numisma, 237. 1996. Pp. 259-289.

FROCHOSO SANCHÉZ, R.: "Los feluses del Emirato Independiente", Numisma, 239. 1997. Pp. 9-73.

IBN HĀFIZ IBRĀHITM, T.: "Adiciones a la numismática de los taifas del Sarq al-Andalus (404-478 / 1013-1085)", Gaceta Numismática, 103. 1991. Pp. 27-36.

MARTÍN ESCUDERO, F.: "El hallazgo omeya de Baena: un tesoro olvidado", Actas IV Jarique de Numismática Andalusí. Canto, A. y Salvatierra. V. (eds.). Jaén. Pp. 8I-94.

MARTINEZ SALVADOR, C.: "La moneda del califato andalusí: algunos aspectos de su organización", V Semana de Estudios Medievales. Nájera, 1994. Nájera, 1995. Pp. 227-231.

MEDINA GOMEZ, A.: Monedas hispano-musulmanas. Manual de lectura y clasificación. Toledo, 1992.

PELLICER I BRU, J.: "Puntualizaciones sobre equivalencias monetarias de las fuentes Andalusís: Consideraciones cronológicas y metrológicas", Gaceta Numismática, 94-95. 1989. Pp. 89- 102.

SÁENZ DíEZ, J. I.: "Los dirhems del 388 de la ceca de Al-Andalus", Numisma, 165-167. 1980. Pp. 21 I-222.

\footnotetext{
10 Alternando diferentes sistemas: Harvard y notas a pie de página; apellidos en mayúscula y/o minúscula; en ocasiones, cuando por primera vez se refiere a un libro no lo muestra acompañado de su cita bibliográfica (veáse por ejemplo Vives p. 29 y Miles p. 31), en concreto estas dos obras tampoco son recogidas en la bibliografía general.

II Cuando son transcritos, no siempre siguen las mismas reglas, veáse pp. 22 y 24 con Mūsa y Yāḥyā.

12 Mezcla datas cristianas o Hégira/Cristiana indistintamente. Igualmente señala H. (Hégira) y J.C. (después de Jesucristo) o no lo señala. 13 Veáse por ejemplo W. p. 25, SIP p. 42 ó SIAM p. 49 nota 61

14 Aparece en la p. 105. En nuestra opinión sería más correcto el uso de peso y peso medio.
} 